\title{
UNEMPLOYMENT AND THE SOCIAL SAFETY NET \\ DURING TRANSITIONS TO A MARKET ECONOMY: EVIDENCE FROM THE CZECH AND SLOVAK REPUBLICS
}

\author{
John C. Ham* \\ Jan Svejnar** \\ Katherine Terrell**
}

First Draft

July 1993

Latest Revision

May 15, 1998

* $\quad$ University of Pittsburgh

** The William Davidson Institute at the University of Michigan Business School and CERGE-EI, Prague

The paper benefited from the comments of two anonymous referees and the editor, and from presentations at Brigham Young University, CERGE-EI, Cornell University, Duke University, McGill University, McMaster University, The Milken Institute, University of Michigan, New York University, Pittsburgh/Carnegie Mellon Universities, Princeton University, University of California at Irvine, UCLA, University of Southern California, University of Texas at Austin, the 1993 NEUDC Conference at Yale University, the 1995 AEA and EEA Meetings, and the 1993 World Bank Workshop on Labor Markets in Eastern Europe and Russia. The authors would like to thank Stepan Jurajda and Eileen Kopchik for exceptional research assistance. Patricia Beeson, Michael Cragg, Curtis Eberwein, John Engberg, Christopher Flinn, David Green, George Jakubson, Julia Lane, Robert Miller, and Viktor Steiner provided many helpful suggestions. The authors would also like to acknowledge support from the National Science Foundation (Grants SBR-951-2001 and SES-921-3310), the National Council for Soviet and East European Research (Contract No. 806-34) and the Grant Agency of the Czech Republic to CERGE-EI. Part of this research was carried out while Ham was a visitor in the Economics Department, Northwestern University and in the Institute for Policy Analysis, University of Toronto. He would also like to thank both institutions for their support and hospitality. All remaining errors are our responsibility. 


\section{Introduction}

The Central and East European (CEE) countries are completing the first decade of a dramatic transition from a centrally planned economic system to a market system. Although economic outcomes have been diverse, all CEE countries (except for the Czech Republic) have experienced rapidly rising and persistently high unemployment rates, which have been accompanied by long spells of unemployment. By contrast, in the Czech Republic the unemployment rate has remained low and unemployment spells have been short (Table 1).

The unemployment crisis in the CEE countries has contributed to a political backlash as disenchanted voters often ousted the first reform governments after a few years. ${ }^{1}$ This experience underscores the importance of two questions. First, why has the unemployment problem in the Czech Republic been much less severe? Second, how can economies in transition strike a balance between (i) reducing government intervention and introducing market incentives, and (ii) providing an adequate social safety net that ensures public support for the transition? In addition to being of academic interest, answers to these questions are essential for policy makers in the CEE countries, in Western governments, and at international institutions such as the World Bank and the International Monetary Fund.

When comparing the Czech experience to that of the other CEE countries, policy makers and researchers are hampered by the difficulty in accounting for differences in relevant laws and institutions, and in the definitions of economic and demographic variables. To minimize this difficulty, we collected parallel micro data sets from the Czech and Slovak Republics. The Slovak Republic (SR) is a natural "comparison" country for the Czech Republic (CR) because the two republics were one country from 1918 until January 1993 (except during World War II). As a result, the republics shared the same laws, 
institutions, currency and government programs.

Despite this common history, the two republics' labor markets have performed substantially differently since the "Velvet Revolution" in November 1989. In January 1990, the unemployment rates in both the Czech and Slovak regions of Czechoslovakia stood at 0.1\%. However, as may be seen 
the generally high unemployment rates experienced in the transition, we estimate the relative effects of various variables on the probability that an individual leaves unemployment (the hazard function) in each republic. We estimate these coefficients for both recipients of unemployment benefits and for non-recipients. We propose a new identification strategy that provides relatively precise estimates of the effects of the UCS on the recipients in the two republics. Within each republic, we compare the experience of recipients and non-recipients to obtain an alternative measure of the impact of the UCS on the duration of unemployment. Since the compensation schemes are similar across the CEE countries (see Section 2 below), our approach should be of general interest to those studying the UCS in the other CEE countries. ${ }^{3}$ Next, we derive and implement an Oaxaca-type decomposition of the difference in the (nonlinear) expected unemployment durations between the CR and SR in order to determine which factors account for the differences between the two countries. Finally, we discuss additional factors that may underlie the econometric results and may be important for explaining the Czech and Slovak differences in unemployment.

The average unemployment spell lasts three to four times longer in Slovakia than in the Czech lands. Our first principal finding, based on the Oaxaca-type decomposition, is that nearly one-third of this difference is explained by differences in the explanatory variables in the two republics. The remaining two-thirds is accounted for by the different behavior of firms, individuals, and institutions in the labor market, as reflected by differences in the coefficients of the hazard functions. (We discuss the factors underlying this result in Section 5.2.) Among the recipients of unemployment benefits, the contribution of the explanatory variables comes mostly from differences in demand conditions between the two republics; relatively little of the difference in expected unemployment comes from differences in the demographic variables. However, for non-recipients most of the contribution of the explanatory

\footnotetext{
${ }^{3}$ For examples of studies that examine the unemployment duration effects of the UCSs in CEE countries see Hunt (1995), Micklewright and Nagy (1994), Puhani (1996) and Wolfe (1997).
} 
variables arises from differences in demographic characteristics of this group between the two republics.

Our second principal finding is that in both republics, the unemployment compensation system has only a moderately negative effect in terms of lengthening an unemployment spell. Thus policy makers in both the low and high unemployment transition economies should have considerable latitude in providing an adequate social safety net without jeopardizing efficiency. This finding is important because the negative socio-political backlash to the transition measures has been significant and an adequate social safety net may be a prerequisite for rallying sufficient popular support to complete the transition.

The paper is organized as follows. In Section 2 we describe the UCS in the CR and SR and compare it to the systems in the other CEE countries. In Section 3 we describe our data and estimation strategy. In Section 4 we discuss the determinants of the probability of leaving unemployment in each republic, focusing on the effects of the UCS. We then compare the expected durations of recipients to non-recipients to obtain an alternative estimate of the effects of the UCS. In Section 5, we decompose the difference in the expected duration of unemployment spells between the CR and SR for both recipients and for non-recipients. Since the econometric results point to differences in individual, firm and institutional behavior, we then discuss the factors underlying these differences. We conclude the paper in Section 6. 


\section{Characteristics of the Unemployment Compensation System}

In this section we describe the principal features of the UCS in the Czech and Slovak Republics and compare them to the features of the systems of the other CEE countries. This description is important for understanding our econometric specification and the applicability of our methodology and findings to the other CEE countries.

\subsection{The Czech and Slovak Unemployment Compensation System}

In January 1990 Czechoslovakia introduced a UCS which was liberal when compared to the U.S. but not when compared to West European systems. Except for one feature noted below, the system was essentially identical in the CR and SR through the end of 1993 (even after their "Velvet Divorce" in January 1993). We focus our discussion on the three main features of the system -eligibility, entitlement and benefits -- during the period covered by our study (from the last quarter of 1991 to the middle of 1993).

Eligibility: Anyone who worked for at least twelve months in the preceding three years was immediately eligible for unemployment benefits, unless the person was fired for cause or quit repeatedly. ${ }^{4}$ Students at the time of graduation from high school or university were also eligible. Until January 1992, individuals out of the labor force were eligible if they had cared for a young child or a sick/disabled relative, or if they were in the military or imprisoned, for twelve months in the previous three years. After January 1992, individuals who had been out of the labor force were no longer eligible.

Entitlement: In 1991, all eligible unemployed were entitled to twelve months of benefits. On January 1, 1992, entitlement was reduced to six months. Since there was no "grandfather clause," those who became unemployed after July 1, 1991 received a maximum of only six months of benefits.

\footnotetext{
${ }^{4}$ Individuals who were fired for cause or quit repeatedly were eligible for unemployment benefits after a six-month waiting period.
} 
Benefits: For most of those who worked before entering unemployment, the level of benefits was set in 1991 at $60 \%$ of the person's previous net wage for the first six months of unemployment. However, individuals who were laid off because of major organizational changes (redundancy) had benefits set at $65 \%$ of their previous wage. ${ }^{5}$ For both groups, the replacement rate fell to $50 \%$ in the second six months of the entitlement period. On January 1, 1992, the replacement rate became $60 \%$ for all workers during the first three months and 50\% during the second three months of their unemployment spell. ${ }^{6}$ Those who had never worked before and recently graduated students received benefits equal to $60 \%$ of the minimum wage in the first half of the entitlement period and $50 \%$ in the second half of this period.

In 1991, a minimum benefit level was set at $60 \%$ of the minimum wage but there was no maximum level. In January 1992, a maximum level equal to $150 \%$ of the minimum wage was imposed. Throughout the period, a family could receive social assistance (welfare) in addition to unemployment compensation if the sum of the unemployment benefits and the income of other household members was less than the household minimum living standard (MLS). ${ }^{7}$

Once benefits expired, the unemployed were eligible for social assistance if their household income was below the MLS. All single individuals were eligible for welfare benefits, while a married person was only eligible if the combined income of the other household members was below the household MLS.

\footnotetext{
${ }^{5}$ Those dismissed for redundancy also received severance pay. In principle, severance pay was treated differently in the two republics until January 1992. In the CR an individual was not eligible for unemployment benefits while collecting severance pay. From January 1990 to January 1992, the Slovak authorities allowed the unemployed to receive severance pay concurrently with unemployment benefits. However, most Slovaks who received severance pay did not collect unemployment benefits until they had exhausted their severance pay.

${ }^{6}$ Throughout 1991-1993, anyone undertaking training received a benefit of $70 \%$ of his/her previous wage during the training period.

${ }^{7}$ The MLS is equivalent to the household poverty line in the U.S. See Terrell and Münich (1995) for a detailed description of the MLS in the CR and Terrell et al. (1995) for an equivalent description for the SR.
} 
Registered Unemployed Who Are Ineligible for Benefits: A significant number of individuals who were ineligible for unemployment benefits registered as unemployed. Some registered in order to obtain the assistance of the district labor office in finding a job. Registration was also a prerequisite for receiving welfare. As noted above, those who did not have the necessary work experience in the previous three years (or its equivalent before January 1992) were ineligible, as were those who were fired for cause or quit repeatedly. Further, if a graduating student started a job and lost it before acquiring twelve months of experience, he/she was not eligible for benefits. ${ }^{8}$

\subsection{A Comparison with the Unemployment Compensation Systems in Other CEE Countries}

There are many similarities in the features of the Central and East European UCSs during the period of our study. By the end of 1991, UCSs had been established in all these countries. We briefly highlight the principal features of these systems. ${ }^{9}$ In terms of eligibility, since 1992 all the CEE countries required a minimum period of previous employment. This minimum period ranged from six months during the preceding year (Bulgaria, Poland and Romania) to one year in the preceding three years (CR, SR and Hungary). A second similarity is the use of fixed entitlement periods that did not vary across workers. This was true in the CR and SR, as well as in Albania, Poland and Romania. ${ }^{10}$ Third, in all of the CEE countries except Albania, benefits were based on fixed replacement rates that did not vary with worker characteristics. Fourth, except for Bulgaria and Poland, replacement rates fell over the entitlement period for all workers. Fifth, all the CEE countries except for Poland imposed a similar maximum level of benefits. ${ }^{11}$ Finally, there was no indexation of benefits for inflation in any of the CEEs.

\footnotetext{
${ }^{8}$ For a discussion of those covered and not covered by unemployment compensation in the U.S., see Blank and Card (1991).

${ }^{9}$ See OECD (1995) for further details.

${ }^{10}$ Since then, Poland has had two entitlement periods, with a higher one for those employed for 25-30 years or in certain regions of the country.

${ }^{11}$ The maximum benefit was a multiple (between 1.4 and 2.0) of the minimum wage.
} 
These features need to be taken into account when developing an econometric approach for estimating the effects of changes in the UCS characteristics on unemployment duration. Moreover, the similarity of the UCS features in the CR and SR to those in the other CEE countries means that our estimation strategy is relevant for the analyses of the UCSs in these other countries.

\section{Data and Estimation Strategy}

\subsection{Data Description}

We collected data on a stratified random sample of 3,000 Czech and 3,000 Slovak men and women who registered at the district labor offices as unemployed between October 1, 1991 and March 31, 1992. ${ }^{12}$ We followed these individuals from the time of their registration to the end of their unemployment spell or the end of July 1993, whichever came first. Since the labor market experience of men and women is likely to differ, here we focus on men. Moreover, we selected individuals who were not in retraining, did not suffer a prolonged illness and had no missing values. This yielded data on 780 men in the CR and 1,063 men in the SR who received unemployment benefits (recipients), and 482 men in the CR and 229 men in the SR who did not receive benefits (non-recipients).

The basic sample statistics for each group are given in Table A1 in the appendix. As may be seen from the table, in the $\mathrm{CR}$ a recipient has a 0.052 average probability of leaving unemployment for a job in a given week, while the average transition rate for a non-recipient was 0.063. In the SR the weekly transition rates from unemployment to employment for recipients (0.020) and for non-recipients (0.019) were much lower than those in the CR. The difference in

\footnotetext{
${ }^{12}$ During this period there were 78 districts in the Czech Republic and 38 districts in the Slovak Republic. We first randomly selected 20 districts in each of the two republics and then randomly selected 150 individuals in each district labor office.
} 
the two labor markets is also illustrated by the fact that in the CR only $11.3 \%$ of the recipients and $16.1 \%$ of the non-recipients did not exit for a job during our sample period, while in the SR the corresponding figures were $34.2 \%$ and $38.2 \% .^{13}$ Moreover, a much smaller proportion of recipients exhausted their benefits in the CR (0.135) than in the SR (0.455). Finally it should be noted that the mean previous wages and unemployment benefits differ only slightly, reflecting the institutional similarities across the CR and SR. We discuss the remaining statistics presented in Table A1 in the next section when we describe the variables included in the econometric model.

\subsection{Econometric Model}

We analyze the Czech and Slovak unemployment spells using a duration model. This model is preferable to a regression model because factors such as demand conditions and unemployment benefits change over an individual's unemployment spell and this nonstationarity cannot be captured in a regression framework. ${ }^{14}$ We denote the hazard function (the probability of leaving unemployment to employment) in week $r$ of an unemployment spell as ${ }^{15}$

$$
\lambda(\mathrm{r} \mid \theta)=(1+\exp (-\mathrm{y}(\mathrm{r} \mid \theta)))^{-1}
$$

where

$$
\mathrm{y}(\mathrm{r} \mid \theta)=\alpha_{0} \mathrm{~B}(\mathrm{r})+\alpha_{1} \mathrm{~W}+\mathrm{g}(\mathrm{E}(\mathrm{r}))+\mathrm{h}(\mathrm{r})+\mathrm{Z}(\mathrm{r}) \gamma+\theta
$$

In equation (2), $B(r)$ denotes unemployment benefits in week $r, W$ is the individual's

\footnotetext{
${ }^{13}$ Note that the probability of leaving unemployment refers to a given week, while the percentage of recipients that did not exit for a job refers to the sample period, which could be as long as 1.75 years.

${ }^{14}$ See e.g., Flinn and Heckman (1982), Heckman and Singer (1984a), Kiefer (1988) and Lancaster (1990). See also Devine and Kiefer (1991) for a comprehensive survey of previous empirical studies.

${ }^{15}$ All variables in equations (1) and (2) are individual-specific. We have omitted the individual subscript for expositional ease. In an earlier version of the paper, we also considered a multiple exit version of the model since a substantial number of individuals in the CR (but not the SR) leave unemployment for self-employment instead of for a new job. We estimated a separate transition rate for finding a new job and for becoming self-employed. However, the data were not rich enough to estimate these transition rates separately. Thus we treat exits to selfemployment as exits to employment in calculating the above hazard.
} 
previous weekly wage, and $g(\bullet)$ is a function of remaining entitlement $E(r)$ in week $r$. We parameterize $g(\bullet)$ as a linear function of: (i) remaining weeks of entitlement, (ii) a dummy for the last week of entitlement before benefits have been exhausted, and (iii) an exhaustion dummy equal to 1 for all weeks after entitlement has been exhausted. We allow for separate coefficients on these last three entitlement variables for married and single men, since single men will most likely be eligible for welfare after exhaustion of benefits and this is not necessarily true for the married men. $^{16}$

The term $h(r)$ represents the effect of duration dependence on the hazard and $\theta$ denotes an unobserved heterogeneity component. In the case of time-constant explanatory variables, it is well known that ignoring unobserved heterogeneity or duration dependence biases the coefficients of the explanatory variables. In our case, both benefits and remaining entitlement are linked to duration, and we would expect the potential bias from ignoring heterogeneity or duration dependence to be more serious than in the case when they are not linked. ${ }^{17}$ As a result, we use a polynomial in log duration to measure duration dependence and we account for unobserved heterogeneity using the Heckman-Singer (1984b) non-parametric approach. ${ }^{18}$ We estimate the

\footnotetext{
${ }^{16}$ We do not have sufficient information to impute welfare benefits for single or married men; therefore we set the value of benefits to zero once an individual exhausts his unemployment compensation. Thus the exhaust dummy (interacted with marital status) implicitly picks up the level of welfare benefits after exhaustion.

${ }^{17}$ For example, assume that there is no duration dependence but that there is unobserved heterogeneity. Consider measuring the effect of lowering benefits at thirteen weeks, which we would expect to raise the hazard. However, the measured hazard in week one could be higher than the average hazard at thirteen weeks because the unobservable characteristics of workers who stay unemployed make them less likely to leave unemployment. If we ignore unobserved heterogeneity, the benefits coefficient will be biased towards zero in absolute value. Alternatively, assume we have negative duration dependence (as is the case in our data) but no unobserved heterogeneity, and consider estimating the effect of changes in entitlement. Since entitlement generally falls as duration increases, ignoring duration dependence will bias the estimated entitlement coefficient toward zero in absolute value.

${ }^{18}$ Following the results of Baker and Melino (1997), we are conservative in choosing the degree of the polynomial and the number of support points of the heterogeneity distribution. (See Section I of the Appendix for more detail.)
} 
model by maximum likelihood (see Section I of the Appendix). Since it is difficult to interpret the parameter estimates of the hazard function, we use these estimates to calculate the effect of changing any given explanatory variable on the expected duration of unemployment.

The term $Z(r)$ contains variables measuring demographic characteristics and demand conditions in week $r$ while the vector $\gamma$ contains the corresponding set of parameters. The means of these variables are given in appendix Table A1. Except for age, the demographic variables are in a dummy variable form. The only variables requiring explanation are the 'recent graduate' and the education variables. The recent graduate variable is coded 1 if an individual graduated within the last year from a university or high school. ${ }^{19}$ We use three dummy variables for educational achievement: i) graduates of a vocational high school, ii) graduates of an academic high school, and iii) those with some post high school (university) education. (The control group consists of those with only a junior high school education, the minimum level of education required by law.)

We use three variables to account for differences in demand conditions. The first two -quarterly data on district unemployment rates and district vacancy rates for the individual's education group -- take on values that change quarterly over the duration of a spell and across

\footnotetext{
${ }^{19}$ Since by definition previous wages do not exist for new graduates, we set their wages to 0 . Thus the new graduate coefficient also picks up the wage effect. This is equivalent to imputing a common real wage for these individuals.
} 
individuals. ${ }^{20}$ The third variable is the real value of per capita industrial production in the district in a given year. ${ }^{21}$ This variable takes on different values across calendar years and across districts. In addition, for each district we use the ratio of the 1991 employment in agriculture to employment in industry to capture the differences in the economic structure across districts at the beginning of the transition. ${ }^{22}$

As may be seen from appendix Table A1, there are substantial differences in the average values of the demand variables between the two republics. In contrast, there are only small differences in the demographic characteristics between (1) the Czech and Slovak recipients and (2) the Czech recipients and non-recipients. The main exception is the proportion of Romany (gypsies), which is higher for non-recipients than recipients in both countries and higher in Slovakia than in the Czech Republic. However, there appear to be more substantial differences between recipients and non-recipients in Slovakia, as well as between the non-recipients in the two republics (see e.g., education, marital status and living in the capital city).

\subsection{Identification of the Unemployment Compensation Parameters}

When estimating the impact of benefits on unemployment durations, it is necessary that the benefit levels vary independently from other determinants of the duration of recipients' spells, particularly previous wages. In our empirical work we find that we have sufficient variation in

\footnotetext{
${ }^{20}$ The denominator in both of these rates is the relevant population group, rather than labor force group, since the number employed by education group and district are not available for this period. We were concerned that the district level data might be too noisy, particularly in the SR where regional differences are smaller than in the CR. To address this issue, we constructed a more aggregate measure: the unemployment (vacancy) rate by education in the individual's district plus the congruent districts. Since the use of this more aggregate measure did not affect the results, we focus on the results for the district variables.

${ }^{21}$ The industrial production variable is available only at an annual frequency. It is a price-weighted composite of total per-capita industrial production in the district in 1991 prices.

${ }^{22}$ We would also like to control for differences in employment in services across and within the two republics. Unfortunately, data on employment in services are not available at the district level for our sample period.
} 
benefit levels to estimate precisely its coefficient in the hazard function. We use five sources of independent variation in benefit levels. First, in 1991 those who were laid off for redundancy had a replacement ratio of $65 \%$ of their previous wage in the first thirteen weeks while the replacement ratio was $60 \%$ for other workers. Second, the replacement ratio dropped to $50 \%$ from thirteenth to twenty-sixth week of compensated unemployment for all individuals. Third, a maximum benefit level was imposed in 1992. Fourth, a number of individuals had their benefits raised to the minimum level of benefits. Fifth, unemployment benefits were not indexed to inflation and hence we discount benefits by monthly movements in the consumer price index in order to capture the erosion of the real value of benefits over time. On the other hand, we assume that the appropriate proxy for the mean of the worker's wage offer distribution is his real wage (in October 1991 prices) at the time he began his spell. Prices and nominal wages rose by approximately 30 per cent from the last quarter of 1991 to the second quarter of 1993, the period covered by our data (Dyba and Svejnar, 1995).

Similarly, when estimating the impact of the length of remaining entitlement on unemployment durations, it is also necessary that the weeks of remaining unemployment compensation to which a recipient is entitled be independent of other determinants of the hazard function, particularly current duration. ${ }^{23}$ In our empirical work, the principal source of this variation in remaining entitlement comes from the significant number of individuals who do not register for unemployment benefits at the time of their job loss. For such individuals, remaining entitlement is not a simple linear function of current duration and initial weeks of entitlement

\footnotetext{
${ }^{23}$ We cannot exploit the fact that individuals in 1991 received a year of entitlement while individuals in 1992 received only six months of entitlement. The change in the system was known as early as October 1991 and, as noted above, individuals beginning a spell in 1991 were not grandfathered. Further, the CR and SR systems were being computerized in 1991, and we were unable to obtain micro data on unemployment spells prior to October 1991.
} 
(which is constant across the sample). ${ }^{24}$ One reason that individuals register late for benefits is that individuals usually exhaust severance pay before collecting benefits. Other individuals simply wait to collect benefits; this phenomenon is similar to the phenomenon of less than full take-up of unemployment benefits in the United States (see e.g., Anderson and Meyer, 1997).

It is worth noting that the variation in benefit levels and remaining entitlement is larger in magnitude than the variation used in studies of unemployment durations in Canada and West European countries. It is probably not as large as the variation found among unemployment insurance recipients in the United States. In our empirical work we find that we have sufficient variation in benefit levels and entitlement to estimate precisely the impact of benefits and entitlement on the duration of unemployment spells.

\subsection{An Alternative Measure of the Impact of Unemployment Compensation System}

We can use the estimated hazard function for recipients to calculate the effect of marginal changes in the UCS on average unemployment duration, e.g., the effect of a one week increase in entitlement. In this section we discuss how we can use data on recipients and non-recipients to obtain an estimate of the impact of an infra-marginal change in the UCS. ${ }^{25}$ First, consider the hypothetical scenario where we make a recipient ineligible for unemployment compensation. Note that a simple comparison of the expected durations of recipients and non-recipients does not yield the correct magnitude since it does not control for potential differences in the characteristics of the recipients and non-recipients. Instead, for each republic we calculate the effect on unemployment duration of letting recipients have the values of their explanatory variables but

\footnotetext{
${ }^{24}$ Using late registrants does complicate the econometric framework. See Section II of the Appendix for a discussion of the relevant issues and the results of our addressing these complications in our empirical work.

${ }^{25}$ See also Marston(1975) and Fallick(1991) for a comparison of recipients and non-recipients. Levine (1993) allows increases in unemployment benefits to affect the duration of non-recipients spells because they may increase recipients' spells. We do not have enough data to implement his approach.
} 
assigning them coefficient values of the non-recipients. ${ }^{26}$ Since the variables relating to unemployment compensation are not available for the non-recipients, we use a smaller set of explanatory (demographic and demand) variables $\mathrm{X}_{\mathrm{nr}}^{*}$ to estimate the hazard rate for the nonrecipients. Denote the same smaller set of variables for recipients as $\mathrm{X}_{\mathrm{r}}^{*}$ and the corresponding parameter estimates for non-recipients and recipients as $\beta_{\mathrm{nr}}^{*}$ and $\beta_{\mathrm{r}}^{*}$, respectively. Formally, we calculate

$$
\operatorname{Diff} 1=\operatorname{ED}\left(\beta_{\mathrm{nr}}^{*}, X_{\mathrm{r}}^{*}\right)-\operatorname{ED}\left(\beta_{\mathrm{r}}^{*}, X_{\mathrm{r}}^{*}\right)
$$

where $E D(\beta, X)$ denotes the expected duration of unemployment at the mean values of the $X \mathrm{~s}^{27}$ (In order to streamline notation, in what follows we simply use $X$ to denote mean values in the expected duration calculations.) We call this "moving someone from being a recipient of unemployment insurance to being a non-recipient."

We also calculate the effect of moving someone from the non-recipient category to the recipient category. To do this we let non-recipients keep the mean values of the explanatory variables but take on the parameter values of the recipients. Formally we calculate

$$
\operatorname{Diff} 2=\operatorname{ED}\left(\beta_{\mathrm{r}}^{*}, X_{\mathrm{nr}}^{*}\right)-\operatorname{ED}\left(\beta_{\mathrm{nr}}^{*}, X_{\mathrm{nr}}^{*}\right) \text {. }
$$

\subsection{Decomposing the Difference in Czech and Slovak Expected Unemployment Duration}

To provide a better understanding of the factors determining the differences in the

\footnotetext{
${ }^{26}$ Ideally we would like to control for unobserved differences between the recipients and non- recipients. To do this we would need to estimate a model with sample selection (see Ham and LaLonde, 1996). To identify and estimate such a model, we need a variable that determines whether someone was a recipient or not, but does not affect their unemployment duration. We could not find a credible exclusion restriction with which to identify the selection model.

${ }^{27}$ See Section III of the Appendix.
} 
expected durations of unemployment in the two republics, we use a non-linear Oaxaca-type decomposition. Let $\beta_{j}$ denote the entire vector of parameter estimates from equation (2) for republic $j$ and $X_{j}$ denote the vector of mean values of the explanatory variables in republic $j$, where $j=c$ represents the $\mathrm{CR}$ and $j=s$ represents the SR. The difference in the expected durations between the Slovak and Czech Republics is given by

$$
\mathrm{ED}_{\mathrm{s}}-\mathrm{ED}_{\mathrm{c}}=\mathrm{ED}\left(\beta_{\mathrm{s}}, \mathrm{X}_{\mathrm{s}}\right)-\mathrm{ED}\left(\beta_{\mathrm{c}}, \mathrm{X}_{\mathrm{c}}\right)
$$

In Section III of the Appendix, we show how we calculate the extent to which the difference in the expected durations is due to: i) differences in the average characteristics of the Czechs and Slovaks $\left(X_{c}\right.$ and $\left.X_{s}\right)$ and ii) differences in the coefficients $\left(\beta_{s}\right.$ and $\left.\beta_{c}\right)$. Moreover, we can decompose the contribution of the explanatory variables into the contribution of: i) demand variables and ii) other variables, including the demographic ones. (We cannot carry out a similar decomposition of the coefficients. See e.g., Oaxaca and Ransom, 1995.) We carry out the decompositions both for recipients and non-recipients.

\section{Factors Affecting the Probability of Leaving Unemployment}

\subsection{The Duration Effect of the Unemployment Compensation Variables}

The estimated effects of changes in the UCS on the probability that an individual will leave unemployment are presented in Table 2. In Panel A of the table, we present the estimates of the hazard coefficients for selected variables for the two republics. ${ }^{28}$ (A negative coefficient indicates that an increase in the variable reduces the exit rate.) In Panel B we use the estimated coefficients of the hazard function to calculate the effect of a given change in each UCS variable on the

\footnotetext{
${ }^{28}$ The estimated effects of all variables are reported in Appendix Tables A2 and A3. Ham, Svejnar and Terrell (1993) provide estimates of the empirical hazard functions.
} 
expected duration of unemployment (in weeks). ${ }^{29}$ Finally, in Panel C we report the elasticity values implied by the expected duration effects of a change in either benefits, entitlement, or the previous wage.

Starting with the results for the CR in column (1) of Table 2, we find that the level of unemployment benefits has a statistically significant coefficient and that a $10 \%$ increase in the level of benefits causes the expected duration of an unemployment spell to rise by 0.6 of a week. Since the average expected duration of recipients is estimated at approximately 16.7 weeks, our results imply a moderate elasticity of unemployment duration with respect to benefits of $0.6 .^{30}$ The estimated coefficients for the remaining weeks of entitlement for single and married men are both significantly negative and almost identical. However, the coefficient for the last week of entitlement is significantly positive for married men while it is negative and insignificant for single men. The difference in these coefficients may reflect the fact that single men will qualify for welfare when they exhaust their benefits while many married men will not. The exhaustion dummy is significantly negative for both single and married men. ${ }^{31}$ The entitlement coefficients imply that an additional week of entitlement results in 0.36 of a week increase in expected duration for all men. (The respective figures for single and married men are quite similar and thus we focus on the overall effect.) The estimated elasticity of expected duration with respect to of entitlement is 0.55 . The coefficient on the previous wage (which proxies the opportunity cost of staying unemployed) is not significantly different from zero at standard confidence levels.

\footnotetext{
${ }^{29}$ Since we do not have a long time-series, we calculate a truncated expected duration (at four years). See Section III of the Appendix.

${ }^{30}$ See Devine and Kiefer, 1991 (Table 5.2) for a summary of comparable benefit elasticities from different hazard function studies. Essentially, our benefit elasticities for the CR and SR are on the lower end of those reported by Devine and Kiefer, while our entitlement elasticities are close to the average values reported by them.

${ }^{31}$ Recall that this dummy also picks up the effect of welfare benefits.
} 
For Slovakia, the relevant results are contained in column (2) of Table $2 .^{32}$ The benefit coefficient is negative as expected and implies an elasticity of only 0.067 . This coefficient is not significantly different from zero, but the coefficient is informative because the $95 \%$ confidence interval is relatively small. We can obtain an upper bound estimate of the elasticity of expected duration with respect to benefits by using the lower bound of the confidence interval for the benefits' coefficient (which will have the greatest disincentive effect). ${ }^{33}$ The resulting estimated upper bound for this elasticity equals 0.096, indicating that the disincentive effect of increasing benefits is quite small in the SR. ${ }^{34}$ The coefficients on remaining entitlement for both single and married men are both negative and significant. The coefficients for the last week of entitlement for single and married men are positive, statistically significant and quite similar. Hence, in contrast to the CR, there is a spike in the probability of exiting unemployment in the last week of entitlement for both married and single men. The coefficients on the benefits exhausted variables are statistically significant, have the expected negative sign and are nearly identical for married and single individuals. Raising entitlement by one week increases the expected duration of unemployment by 0.93 of a week. (Again, the effects for single and married men are quite similar.) The estimated elasticity of expected duration with respect to raising entitlement is 0.41 , which again represents a moderate disincentive effect. The previous wage has a positive coefficient and is statistically significant. A $10 \%$ increase in the previous weekly wage leads to a 1.51 week decrease in expected duration, implying an elasticity of about -0.25 . Thus in the SR, those with a higher opportunity cost of their time leave unemployment earlier.

\footnotetext{
${ }^{32}$ The SR hazard coefficients are statistically different from the Czech coefficients using a likelihood ratio test.

${ }^{33}$ The lower bound of the confidence interval is $-7.98-(1.96 * 6.36)=-20.45$.

${ }^{34}$ The effect of raising benefits by $10 \%$ using the lower bound estimate of the benefits' coefficient is to increase duration by 0.57 week. Thus the absolute magnitude of the changes of raising benefits is similar in the two republics. However, because the base duration is so much larger in Slovakia, the estimated benefits' elasticity is much smaller in the SR.
} 


\subsection{Estimates of the Other Coefficients of the Hazard Function}

The full set of coefficient estimates for recipients and non-recipients are contained in Appendix Table A2 and the corresponding expected duration calculations are reported in Table A3. In these tables, the estimates for Czech and Slovak recipients using the full model are contained in columns (1) and (4), respectively. These are used to carry out the calculations for equation (5). We report in columns (2) and (5) of the tables the results from the smaller model for recipients in the CR and SR, respectively. These are used to carry out the calculations described by equations (3) and (4) to move individuals across the recipient and non-recipient categories. Finally, columns (3) and (6) report the results (from the smaller model) for nonrecipients in each republic. These coefficients are used to carry out the calculations described in equations (3), (4) and (5). ${ }^{35}$

Our estimation yields a number of interesting results for the demographic and demand variables which are qualitatively similar across both republics. Unemployment duration increases with age. Men with the lowest level of education (junior high school) generally do substantially worse than those in the higher educational groups. Married men have shorter unemployment durations than single men; Romanies have much longer unemployment durations than nonRomanies. The handicapped generally have substantially longer durations than the nonhandicapped. The demand variables clearly play a role and have the expected signs, although the relative significance of the individual variables varies across the hazards, reflecting unavoidable multicollinarity across these variables. ${ }^{36}$ Differences in the agricultural-industry structure across districts do not play much of a role in determining the probability of leaving unemployment.

\footnotetext{
${ }^{35}$ The likelihood function for the non-recipients was poorly behaved, indicating that the smaller model is still too rich for the relatively small number of individuals in this group. After we eliminated the vacancy rate from the specification for this group, this problem with the likelihood function disappeared.

${ }^{36}$ In unreported results, we found that each variable was statistically significant for the recipients if we dropped the other two variables.
} 
In general, we find a broadly similar pattern between the CR and SR in terms of the expected duration effects relative to the base expected duration. This similarity is important because it indicates that there may be a systematic effect of the transition across the two countries. However, because unemployment spells are much longer in the SR than the CR, the absolute differences in the demographic effects across the two republics are very large and it is these differences that are likely to be the relevant statistics for targeting labor market expenditures. In particular, single men with little education are a natural group to target in the SR and other CEEs.

\subsection{Recipients vs. Non-Recipients}

In this section we report the effect on the expected duration of unemployment of moving an individual: i) from the recipient category to the non-recipient category and ii) from the nonrecipient to the recipient category. These calculations, presented in Table 3, provide estimates of the effects of infra-marginal changes in the UCS. For the CR we see that the base expected duration of an unemployment spell for recipients (using the smaller model) is 17.9 weeks (row 1) and for non-recipients it is 15.9 weeks (row 2). This implies that if we ignore the differences in characteristics between the recipients and non-recipients in $\mathrm{CR}$, we find that moving a recipient to the non-recipient category would reduce his average spell by $6.3 \%$. In contrast, when we allow for the recipients to behave like non-recipients using equation (3), we find (in row 5) that moving an individual from the recipient to the non-recipient category reduces his unemployment duration by 4.2 weeks or $23.5 \%$. Alternatively, when we use equation (4), we find (in row 6) that moving someone from the non-recipient to the recipient category increases his unemployment duration by $9.8 \%$. 
In the case of the SR, a comparison of the top two rows of Table 3 indicates that the base expected duration for non-recipients is 0.4 weeks $(0.7 \%)$ shorter than that for recipients. However, controlling for differences in using equation (3), one finds that moving a recipient to the non-recipient category decreases unemployment duration by 9.0 weeks or $16.6 \%$ (row 5). Alternatively, using equation (4) we estimate in row 6 that moving a non-recipient to the recipient category increases unemployment duration by $19.5 \% .^{37}$

Since these experiments correspond to drastic changes in public policy, we consider these effects to be moderate. ${ }^{38}$ A related important finding from Table 3 is that the difference in expected durations between the $\mathrm{CR}$ and $\mathrm{SR}$ is much greater than the difference between recipients and non-recipients within either republic.

\footnotetext{
${ }^{37}$ As noted above, we dropped vacancies from the specification for the SR non-recipients. We calculated equations (3) and (4) with and without vacancies dropped from the specification for SR recipients. This change had no effect on the estimated differences. We also calculated the decomposition in equation (5) with and without vacancies in the $\mathrm{CR}$ non-recipient specification, and again there was no difference in the estimates.

${ }^{38}$ An alternative approach to this question would be to calculate the expected duration of unemployment using the estimates of the recipient hazard with entitlement and benefits set equal to zero. One could compare this measure with the base expected duration for recipients in Table A3, acknowledging that this is extrapolating well beyond the experience of recipients in the sample. One problem in this approach is how to handle the benefits exhausted variable, since this will pick up: i) the difference in unemployment compensation and social assistance and ii) duration dependence. To avoid this problem, we set the benefits exhausted dummy equal to zero and set benefits equal to social assistance (but keep entitlement equal to zero) when making this calculation. Using this approach, we find that moving someone from the recipient to non-recipient category reduces unemployment duration by $49.3 \%$ in the CR and by $40.3 \%$ in the SR.
} 


\section{Explaining the Difference Between the Czech and Slovak Unemployment Duration}

\subsection{Oaxaca-Type Decompositions}

An important contribution of this paper consists of investigating the differences in unemployment durations in the CR and SR using the Oaxaca type decompositions. From Table 4 we see that during the period of our study, the average recipient in Slovakia was unemployed 43.0 weeks longer than the typical recipient in the Czech Republic. The decomposition for recipients in Table 4 indicates that 13.1 weeks $(30.5 \%)$ of the difference in expected duration between the two republics is due to differences in the explanatory variables and 29.9 weeks $(69.5 \%)$ is accounted for by differences in the estimated coefficients. Interestingly, virtually none of the contribution of the explanatory variables is driven by differences in demographic variables between the two republics. Instead, this comes almost entirely from the demand and industry structure variables. The finding that over two thirds of the difference in unemployment duration between the two republics comes from differences in the coefficients suggests that the functioning of labor market institutions and the behavior of firms and agents in the labor market is very different in the two republics. We address this issue presently.

From column 3 of Table 4 we see that the average Slovak non-recipient was unemployed 38.0 weeks longer than the typical Czech non-recipient. Of this difference, 11 weeks (or 29\%) is accounted for by differences in the explanatory variables and 27 weeks (71\%) is accounted for by differences in the estimated coefficients; now about three-quarters of the contribution of the difference in the explanatory variables is coming from the difference in demographic variables. Thus, unlike the case of recipients, among non-recipients the differences in demographic variables play a role in explaining the difference in the expected durations between the CR and SR. As pointed out in Section 3.2, there are important differences in the demographic compositions of the 
non-recipients in the two republics in terms of the proportions of junior high school education, Romany, marital status, and living in the capital city. However, again the large portion explained by the differences in the estimated coefficients suggests that there is an important difference in the functioning of labor market institutions, firms and individuals in the two republics.

\subsection{Factors Underlying the Differences in Estimated Coefficients}

The differences in the estimated coefficients presumably reflect factors such as additional observed and unobserved differences in the structure of the two economies and different responses of firms, individuals and institutions in the labor market. On the basis of interviews that we carried out with policy makers in the two countries, as well as our reading of other studies, we have identified several factors that may be important in accounting for the role played by the differences in coefficients in the decompositions: ${ }^{39}$

(i) In the early 1990s, the growth of the service sector was much larger in the Czech lands and the growth of small firms was much higher in the CR than in the SR. ${ }^{40}$ This growth could not be accurately measured (at any level of aggregation) since official statistics were only gathered systematically for firms with 25 or more employees.

(ii) Privatization was carried out more quickly in the CR. By 1993, 53.5\% of all workers were in private firms in CR lands, compared to only $32.0 \%$ in the SR. This phenomenon is impossible to measure at the district level, but it is important because much of the new hiring is likely to have been done by private firms. ${ }^{41}$

(iii) The age and location of factories differs across the two republics. The Czech lands

\footnotetext{
${ }^{39}$ Some of these factors may also explain the difference in observed local demand conditions.

${ }^{40}$ See e.g., Horalek (1993) and Vavro (1992).

${ }^{41}$ Czech and Slovak Statistical Yearbooks, 1994.
} 
have factories that tend to be older than those in the SR, but their location was chosen by market forces before communism. Slovakia was industrialized after the communist takeover and planners determined the location of Slovak factories with little regard to the proximity of raw materials or market transportation costs. It is possible that the location factor dominated the capital vintage effect and resulted in lower re-employment probabilities in the SR.

(iv) The CR attracted over ten times as much foreign direct investment as the SR in the early to mid 1990s. ${ }^{42}$

(v) Slovakia was much harder hit than the CR by the decline in military production. ${ }^{43}$ Interestingly, much of the relative decline occurred before, rather than during, the transition. However, the artificially maintained full employment under central planning meant that this labor redundancy manifested itself when market forces started to operate in the early 1990s. Indeed, the peak in Czechoslovak military production occurred in 1987, when military production is estimated to have accounted for 3\% of total industrial production and generated 73,000 direct jobs and 50,000 to 70,000 indirect jobs. At this time, the value of Slovakia's military production was $50 \%$ above that of the Czech Republic. ${ }^{44}$ In 1988 military production started to decline in both republics, but the decline was much greater in Slovakia. In the 1988-90 period, the value of military production (in constant prices) dropped by $48 \%$ in the SR and $35 \%$ in the CR. The real value of military production fell by an additional two-thirds between 1990 and 1992, and the rate of decline may have been slightly faster in the SR than in the CR (Ivanek, 1994). ${ }^{45}$

\footnotetext{
${ }^{42}$ E.B.R.d. Transition Reports 1996 and 1997.

${ }^{43}$ In the late 1980s, the Visegrad countries were the fifth largest arms exporters in the world. In 1989, their exports equaled $\$ 600$ million (Milivojevic, 1995).

${ }^{44}$ Since Slovak labor force is almost exactly one-half of the Czech labor force, the extent of military production relative to the size of the economy was clearly much larger in Slovakia than in the Czech Republic.

${ }^{45}$ An offsetting factor was the fact that the Czechoslovak federal government contributed significantly to the
} 
(vi) It has been easier for the Czechs than for the Slovaks to work in neighboring western countries. The CR has a border with (former West) Germany, whereas the SR does not, and Germany pursued lenient policies toward guest workers from former Czechoslovakia. ${ }^{46}$ Moreover, the CR has a longer border with Austria than the SR.

(vii) Finally, from discussions with policy makers and district labor officers in both republics, it appears that in these early years the Czech officials were stricter in enforcing the eligibility and entitlement requirements of the UCS than the Slovak officials. This result is consistent with the larger ratio of non-recipients to recipients in the CR sample as compared to the SR sample. ${ }^{47}$

\section{Concluding Remarks}

Our first principal finding comes from the decomposition of the determinants of the expected durations of unemployment in the Czech and Slovak Republics. We find that two-thirds of this difference is explained by differences in the estimated coefficients of the hazard function. Likely explanations for this result include the more rapid growth of the small-scale, private sector and the service sector in the $\mathrm{CR}$ as compared to the SR, the relative impact of the decline in military production in the two republics, differences in the response of the manufacturing sector to market forces (arising in part from differences in the age and location of factories between the two republics), and the much larger level of foreign investment in the CR. Differences in the

conversion efforts of the military producers - about \$50 million in 1991 and \$35 million in 1992. These subsidies tended to mitigate the relative unemployment levels in the two republics, as three-fourths of the subsidy in each year went to producers in Slovakia.

${ }^{46}$ In the southern German State of Bavaria, workers from former Czechoslovakia were even allowed to work without a work permit.

${ }^{47}$ Note that the difference in enforcement cannot be the only factor at work, given the large difference in expected duration of non-recipients between the CR and SR. 
enforcement of the unemployment compensation system in the two republics also are likely to have contributed to differences in the hazard coefficients between the CR and SR. The remaining one-third of the difference in the durations of the unemployment spells in the two republics is explained by differences in the explanatory variables. For those who receive unemployment benefits (recipients), we find that about one-third of this difference is explained by differences in the levels of local demand variables and a variable measuring structural differences at the district level. However, among non-recipients, differences in demographic characteristics play a more important role than differences in demand factors between the CR and SR.

Our second principal finding concerns the effect of the unemployment compensation scheme, which was identical in the Czech and Slovak republics. Using two different methods, we estimate that this system has moderate effects on the duration of unemployment spells in both republics. This result suggests that policy makers in governments and international agencies have considerable latitude in providing a safety net without endangering efficiency. In view of the similarity between the unemployment situation in Slovakia and the other Central and East European countries, this result is also relevant for policy in other transition economies. 


\section{REFERENCES}

Anderson, P. and B. Meyer (1997) "Unemployment Insurance Take-Up Rates and the AfterTax Value of Benefits," Quarterly Journal of Economics, 62:913-937.

Baker, M. and A. Melino (1997) "Duration Dependence and Unobserved Heterogeneity: A Monte Carlo Study" mimeo, University of Toronto, August 1997.

Blanchard, O. (1997) The Economics of Post-Communist Transition, Clarendon Lectures, Oxford University Press.

Blank, R. and D. Card (1991) "Recent Trends in Insured and Uninsured Unemployment: Is There an Explanation?" Quarterly Journal of Economics, 106:1157-1189.

Czech Statistical Office (1994) Czech Statistical Yearbook.

Devine, T. and N. Kiefer (1991) Empirical Labor Economics, Oxford University Press.

Dyba, K. and J. Svejnar (1995) "Recent Economic Performance in the Czech Republic," In: Svejnar, J. (ed.), The Czech Republic and Economic Transition in Eastern Europe, Academic Press.

European Bank for Reconstruction, EBRD (1996 and 1997) Transition Report.

Fallick, B. (1991) "Unemployment Insurance and the Rate of Reemployment of Displaced Workers," Review of Economics and Statistics, 73:228-235.

Flinn, C. and J. Heckman (1982) "Models for the Analysis of Labor Force Dynamics," In: R. Basmann and G. Rhodes (eds.), Advances in Econometrics, 1:35-95.

Ham, J. and LaLonde, R. (1996) "The Effect of Sample Selection and Initial Conditions in Duration Models: Evidence From Experimental Data on Training," Econometrica, 64:175-205.

Ham, J. and S. Rea (1987) "Unemployment Insurance and Male Unemployment Duration in Canada," Journal of Labor Economics, 5:325-353.

Ham, J., J. Svejnar and K. Terrell (1993) "The Emergence of Unemployment in the Czech and Slovak Republics," Comparative Economic Studies, 35:121-134.

(1995) "The Czech and Slovak Labor Markets during the Transition," In: S. Commander and F. Coricelli (eds.), Unemployment, Restructuring, and Labor Markets in East Europe and Russia, The World Bank.

(1996) "Unemployment and the Social Safety Net During the Transition to a Market Economy: Evidence from Czech and Slovak Men," William Davidson Institute Working paper No. 34, University of Michigan.

Heckman, J. and B. Singer (1984a) "Econometric Duration Analysis," Journal of Econometrics, 24:63-132. 
(1984b) "A Method for Minimizing the Impact of Distributional Assumptions in Econometric Models for Duration Data," Econometrica, 52:271-320.

Hunt, J. (1995) "The Effect of Unemployment Compensation on Unemployment Duration in Germany," Journal of Labor Economics, 13:88-120.

Horalek, M. (1993) "Zamestnanost a Nezamestnanost v Ceske Republice: 1991-93"

['Employment and Unemployment in the Czech Republic: 1991-93']. Friedrich Ebert Foundation Project, Bonn, Germany.

Judge, J., W. Griffiths, R. Hill and T.-C. Lee (1980) The Theory and Practice of Econometrics, John Wiley and Sons.

Ivanek, L. (1994) "Ekonomicke problemy konverze zbrojni vyroby," Mezinarodni Vztahy, 1:42-49.

Lancaster, T. (1990) The Econometric Analysis of Transition Data, Econometric Society Monograph, Cambridge University Press.

Levine, P. (1993) "Spillover Effects Between Insured and Uninsured Unemployed," Industrial and Labor Relations Review, 47:73-86.

Marston (1975) "The Impact of Unemployment Insurance on Job Search," Brookings Papers on Economic Activity, 1:13-48.

Micklewright, J. and G. Nagy (1994) "Unemployment Insurance and Disincentives in Hungary," CEPR (Centre for Economic Policy Research) Discussion Paper 1118.

Milivojevic, Marko (1995) "Uncertain Future: Armaments Production and Exports in Central and Eastern Europe," Army and Defense Quarterly Journal, 125:77-79.

Oaxaca, R. and M. Ransom (1995) "Identification in Detailed Wage Decompositions," mimeo, Brigham Young University, October.

O.E.C.D. (1995) Employment Observer, Paris, May.

Puhani, P (1996) "Poland on the Dole: Unemployment Benefits, Training and Long-Term Unemployment during Transition,” ZEW Discussion Paper No. 96-30, Mannheim.

Slovak Statistical Office (1994) Slovak Statistical Yearbook.

Terrell, K., and D. Münich (1995) "Evidence on the Implementation and Effectiveness of Active and Passive Labor Policies in the Czech Republic," In: Lessons from Labour Market Policies in the Transition Countries, OECD.

Terrell, K., M. Lubyova and M. Stapec (1995) "Evidence on the Implementation and Effectiveness of Active and Passive Labor Policies in Slovakia," In: Lessons from Labour Market Policies in the Transition Countries, OECD. 
Vavro, A. (1992) "Pricin rozdielneho vyvoja nezamestnanosti v SR a CR" ['Analysis of the Reasons for the Evolution of Different Unemployment Rates in the Slovak Republic and Czech Republic'] Bratislava, Slovak Commission for Economic Strategy.

Wolff, J. (1997) "Unemployment Benefits and Incentives in Hungary: New Evidence," Davidson Institute Working Paper No. 111, University of Michigan. 